\title{
Design and Manufacturing of a Pneumatic Driven Compression Spring Fatigue Machine
}

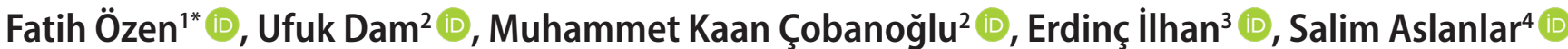 \\ 'Department of Metallurgical and Materials Engineering, Faculty of Technology, Sakarya University of Applied Sciences, Batman, Turkey \\ ${ }^{2}$ Atasan Metal San. Tic. Ltd. Şti., 1. Organized Industrial Zone, 2. Street, No:15, Arifiye, 54580, Sakarya, Turkey \\ ${ }^{3}$ Department of Machinery and Metal Technologies, Sakarya Vocational School, Sakarya University of Applied Sciences, 54290, Sakarya, Turkey \\ ${ }^{4}$ Department Department of Metallurgical and Materials Engineering, Faculty of Technology, Sakarya University of Applied Sciences, Sakarya, \\ Turkey
}

\begin{abstract}
The fatigue life of springs is an issue that has not been studied in detail and is of high importance. Damage to the springs during operation can cause major irreversible damages. Since the microstructural properties and multiple parameters affects fatigue life of the springs to a high degree, fatigue analysis with FEM and numerical analysis methods cannot give a clear result. It should be experimented with specially designed fatigue machines. In this study, a helical compression spring fatigue device simulating the real fatigue conditions was designed and produced. A compression tray have been designed in which 12 compression springs could be fasten together in order to achieve the average fatigue values under the same conditions. Machine design and pneumatic elements was determined in view of design calculations. Electrical control circuits and pneumatic system design was also studied in detail. Then, manufacturing of the designed machine was implemented.
\end{abstract}

Keywords: Compression springs, fatigue, spring fatigue.

\section{INTORDUCTION}

Springs are widely used in machinery, tools and equipment for many purposes such as energy storage and vibration damping. Prolonged vibration or oscillation and cycles induces crack propagation from the weak points on the spring. These crack initiations begin with the notch effect created by the external surface or the irregularities within the microstructure. As a result of the spring fatigue or unexpectedly ending its life, the machine can undergo irreversible damage to its dynamic structure [1].

Various techniques are used to calculate fatigue life of the springs during design. Some of them have been tried to calculate the spring life using the FEM (finite element method) method [2]. Other methods are various mathematical and numerical models that have been put forward $[3,4]$. Although numerical models are used, there are various differences among these thecniques [5]. The main reason for the differences is due to outer and intrinsic factors such as microstructure characterization, surface hardness, surface roughness, application temperature and application frequencies [6, 7]. For this reason, simulating the fatigue of the springs in a real environment will give the most realistic re- sult. Thus, irreversible damages can be prevented by determining the service life of the springs with the most accurate way [8].

Helical compression springs are among the most used spring types in the industry. This type of springs can be used in high-stress ranges where operating conditions are critical such as engines, pumps and valves [9]. The fatigue life of helical compression springs depends on many factors including the condition of the outer surface, surface roughness, internal structure of the material, discontinuities in the material, working load, capacity, and frequency [10]. Therefore, compression springs should be tested under real conditions.

There are many spring fatigue machine designs in the industry. However, no study has been encountered that determines the life of compression springs produced from high strength wires driven with a pneumatic system. Fatigue testing applied to multiple compression springs was not also coincided in the literature. In this study, a fatigue machine simulating the working conditions of compression springs was designed and produced. The operation and design of the mechanical, electrical, pneumatic systems of the machine were carried out. The working efficiency of the fatigue 
machine manufactured within the framework of the determined designs was examined.

\section{MODELLING AND DESIGN}

\subsection{Compression spring design for fatigue tests}

Before designing the compression spring fatigue machine, spring dimensions and working ranges to be used for the experiment should be specified. In Figure 1, the dimensions of a compression spring that can be used in the fatigue machine are determined. $\mathrm{L}_{0}$ represents uncompressed spring length, $\mathrm{L}_{1}$ represents first compression length, and $\mathrm{L}_{2}$ represents second compression length.

After the compression springs are produced in length $\mathrm{L}_{0}$, it is expected to generate force between working intervals of $\mathrm{L}_{1}$ and $\mathrm{L}_{2}$ through its minimum the working life. At the end of fatigue life, the main goal is to have no or very low loss of compression force. Therefore, a device must be arranged to compress the springs between $L_{1}$ and $L_{2}$ lengths.

In addition, by increasing the number of samples, the most statistically accurate fatigue life can be determined. Therefore, the most accurate design can be made by compressing many springs between two plates at the same intervals.

Force plates should be designed according to the size and capacity of the springs to be used in the spring fatigue machine. For this reason, it is necessary to standardize the dimensions of the springs that will be subjected to spring compression. The other purpose of this standardization is that the movements of the springs must be restricted by design in order to simulate them with a healthy way. Our spring samples must be in certain size intervals in order to be limited in terms of design. For this reason, the most used spring for experiments in Figure 1 has been chosen as the dimensional reference. Also, the compression lengths $\mathrm{L}_{1}$ and $\mathrm{L}_{2}$ are the same as the real-life compression spacing at the workplace.

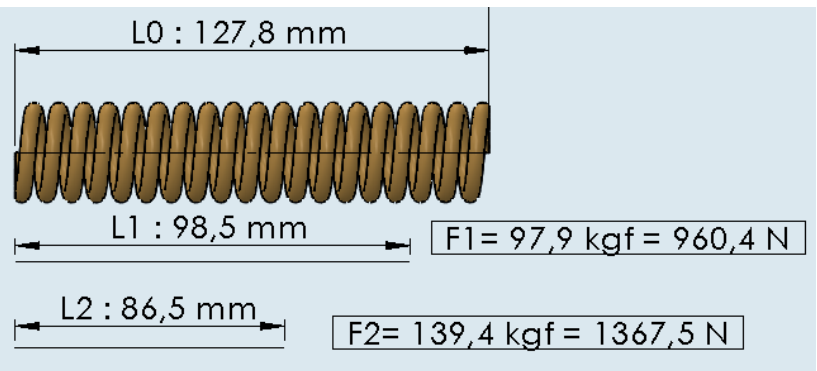

Figure 1. Compression spring sample design that to be tested.

In order to measure the forces between the lengths of $\mathrm{L}_{0}$ $\mathrm{L}_{1}$ and $\mathrm{L}_{0}-\mathrm{L}_{2}$, the spring coefficient must be calculated. The spring coefficient can be determined by the force under two arbitrary shortening. Accordingly, a force of $139.4 \mathrm{kgf}$ was obtained from the compression of the spring used as test reference to $98.5 \mathrm{~mm}, 97.4 \mathrm{kgf}$ and $86.5 \mathrm{~mm}$ compression. If we convert the spring coefficient (1) into formula (2) according to the standard size and material;

$$
F=k . \mathrm{x}
$$

$$
\begin{aligned}
& k=\frac{F 2-F 1}{\mathrm{~L} 2-\mathrm{L} 1} \\
& k=\frac{139.4-97.9}{98.5-86.5} \\
& k=3.4 \mathrm{Kgf} / \mathrm{mm}
\end{aligned}
$$

According to the spring coefficient obtained, the forces obtained in L0 and L1 and L2 compression lengths are specified in (5) and (6).

$$
\begin{aligned}
& \mathrm{F}_{1}=(\mathrm{L} 0-\mathrm{L} 1) \cdot \mathrm{k}=(127.8-98.5) \times 3.4=99.9 \mathrm{kgf} \\
& \mathrm{F}_{2}=(\mathrm{L} 0-\mathrm{L} 2) . \mathrm{k}=(127.8-86.5) \times 3.4=140.8 \mathrm{kgf}
\end{aligned}
$$

Figure 2 shows the fastening mechanism that ensures the fatigue of 12 springs at the same time. Care should be taken to ensure that the diameter of the springs is larger than the maximum compressed diameter. Otherwise, the same working condition cannot be achieved. A pin passing through the center was also added to the design to prevent the springs from dislodging and deflection.

The spring fatigue machine design is shown in Figures 3 and 4. The springs placed between the upper and lower compression plates with number of 4 and 8 respectively are provided

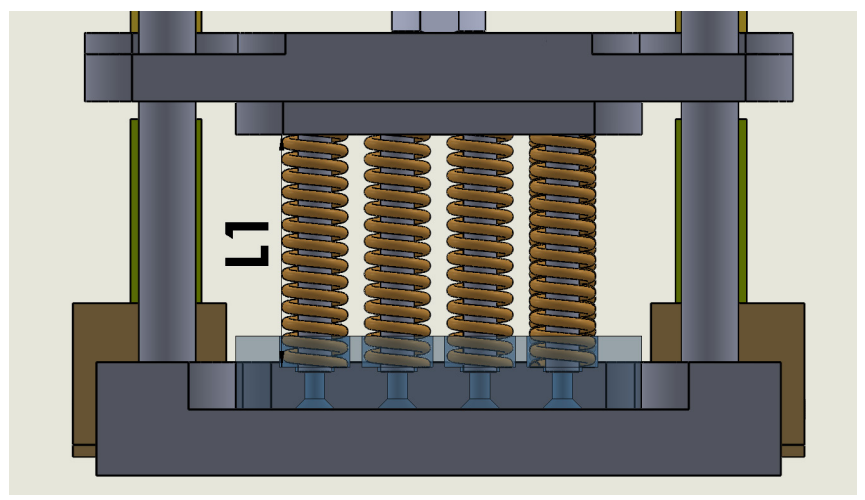

Figure 2. Positioning, design and the layout of the compression spring assembly.

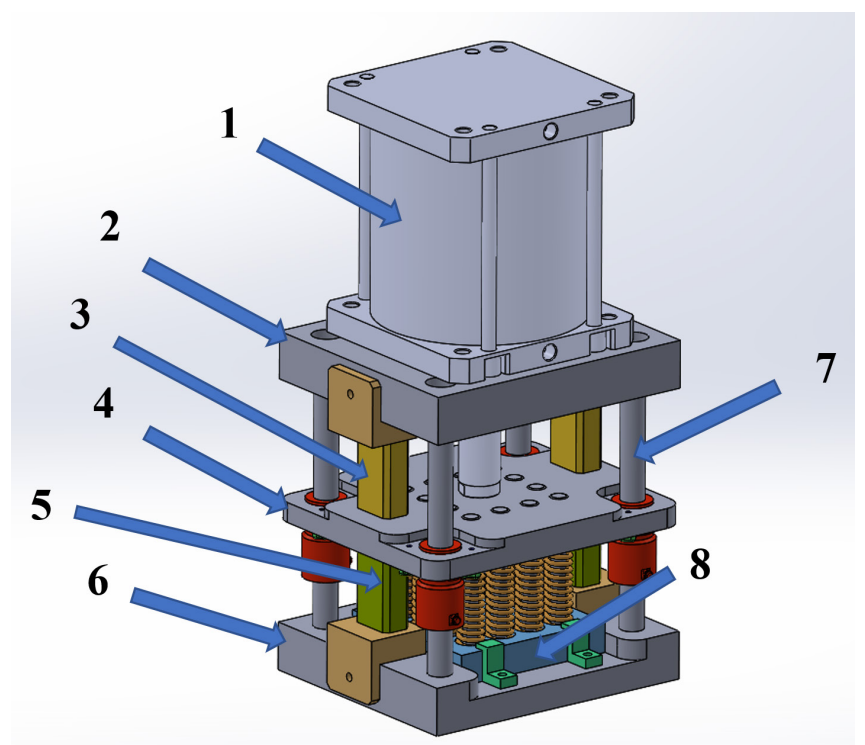

Figure 3. Compression spring fatigue machine design from isometric view. 
with axial bearing with 4 column-bushing pairs number of 7 . This bearing system is designed as dry bearing. Spring compression action is provided by a pneumatic cylinder. Stop block with number of 3 and 5 are used to restrict pneumatic cylinder movement. It is possible to test different lengths by changing the length of the stop blocks according to different compression conditions.

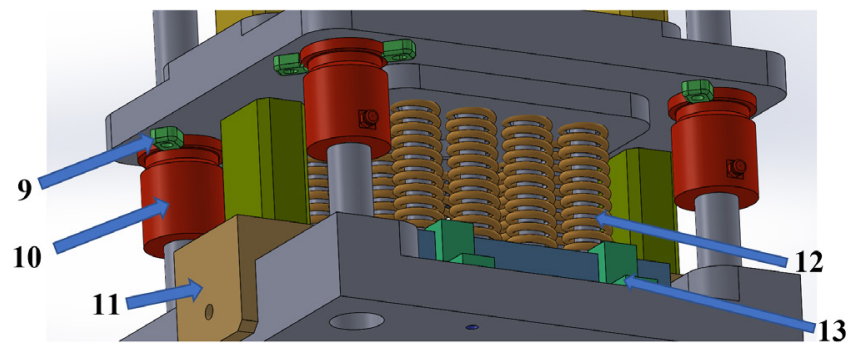

Figure 4. Compression spring fatigue machine design from detail view.

Table 1. The assembly list for the compression spring fatigue machine.

\begin{tabular}{|c|c|c|}
\hline No & Part name & Piece \\
\hline 1 & Pneumatic cylinder & 1 \\
\hline 2 & Upper plate & 1 \\
\hline 3 & Upper stop block & 2 \\
\hline 4 & Support plate & 1 \\
\hline 5 & Lower stop block & 2 \\
\hline 6 & Lower plate & 1 \\
\hline 7 & Column & 4 \\
\hline 8 & Spring seat plate & 1 \\
\hline 9 & Bush holder & 8 \\
\hline 10 & Bronze guide bush & 4 \\
\hline 11 & Stop block holders & 4 \\
\hline 12 & Spring guide shaft & 12 \\
\hline 13 & Spring holder & 2 \\
\hline
\end{tabular}

\subsection{Sizing of pneumatic drive piston}

In the design, the drive force to be applied to the compression springs is designed to be carried out from a pneumatic cylinder with the appropriate force. The force applied by the pneumatic cylinder is directly proportional to the cylinder surface area and the applied air pressure. The standard air pressure used in factory systems is used as $6 \pm 0.5$ bar (600.000 Pa). To ensure the compression of the spring, a force greater than the compression force of the springs must be obtained. The cylinder diameter to be driven is selected as $200 \mathrm{~mm}$. In addition, the double-acting cylinder was selected to return again by air power. The control of whether the selected diameter is greater than the applied force is made in (6).

$$
\begin{aligned}
& \mathrm{A}=\Pi \times \mathrm{r}^{2}=\Pi \times 0,1^{2}=0.0314 \mathrm{~m}^{2} \\
& \mathrm{~F}=\mathrm{P} . \mathrm{A} ; \mathrm{F}=600.000 \times 0.0314 \\
& \mathrm{~F}_{\text {Cylinder }}=18840 \mathrm{~N}=1920.489 \mathrm{kgf} \\
& \mathrm{F}_{\text {total comp }}=\mathrm{n} . \mathrm{F}_{\text {comp single }} ; \mathrm{F}_{\text {total comp }}=12.140 .8=1689.6 \mathrm{kgf} \\
& \mathrm{F}_{\text {Cylnder }}>\mathrm{F}_{\text {toatal comp }}
\end{aligned}
$$

$1920.489 \mathrm{kgf}>1689.6 \mathrm{kgf}$ with this result, It is concluded that the pneumatic cylinder is suitable.

\subsection{Electrical equipment design}

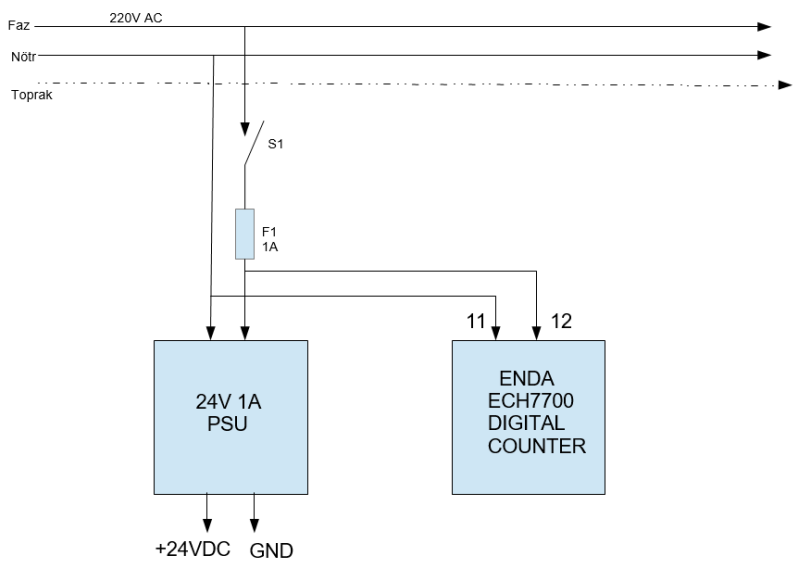

Figure 5. Scheme received from the $220 \mathrm{~V}$ electric source.

The electrical equipment of the spring fatigue device is shown in Figures 5 and 6 . Figure 5 shows that the power taken from the $220 \mathrm{~V}$ mains supply feeds the $24 \mathrm{~V}$ power supply and the ENDA 7700 digital counter. In addition, a 2 A fuse has been installed in order to protect the device in case the power drawn from the network is overloaded.

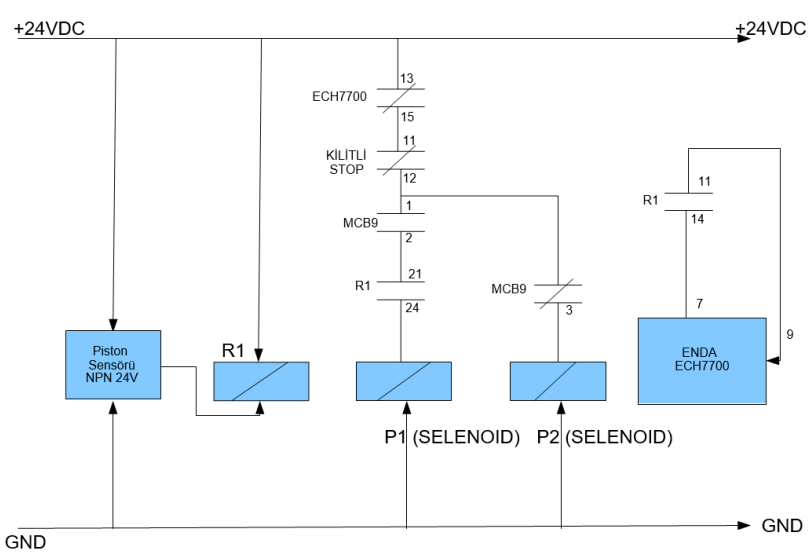

Figure 6. The main electrical scheme of compression spring fatigue machine.

Figure 6 shows the electrical diagram of compression spring fatigue machine fed by $24 \mathrm{~V}$ supply. Accordingly, the RZT1 position sensor mounted on the pneumatic piston was positioned at the off position. When the sensor generate signals, it indicates that the piston springs are in the maximum compression position and the cylinder is completely down. The resulting signal controls the R1 switch. R1 switch is also connected to P1 solenoid. The MCB9 timer relay is set to 0.5 seconds. The MCB9 timer relay is connected to both solenoids. The MCB9 timer relay activates solenoid P1 if it is on and solenoid P2 is off. However, the completion of the circuit depends on the allowance of the emergency stop and the counter. Since the counter is activated with the R1 switch, it will operate under normal conditions. However, the counter will not work when R1 is not turned on. Thus, possible unforeseen errors are prevented. Emergency stop is normally off and connected to the main solenoid control line. It operates normally open like a counter, it cuts the circuit communication when the emergency stop button is pressed, and ensures the test is stopped. The electrical equipment used in 
the device is shown in Table 2.

Table 2. Electrical equipment used in the compression spring fatigue machine.

\begin{tabular}{|c|c|c|}
\hline No & Electrical equipment & Piece \\
\hline 1 & $5 / 224 \mathrm{~V}$ double coil pneumatic valve & 1 \\
\hline 2 & MCB-9 multifunction time relay & 1 \\
\hline 3 & $24 \mathrm{~V}$ relay & 1 \\
\hline 4 & $24 \mathrm{~V}$ power supply & 1 \\
\hline 5 & 2 A fuse & 1 \\
\hline 6 & Emergency stop button & 1 \\
\hline 7 & Ech7700 counter & 1 \\
\hline 8 & RZT1 sensor & 1 \\
\hline
\end{tabular}

\subsection{Machine design and manufacturing}

The assembled version of the designed compression spring fatigue machine is as in Figure 7. All plates are made of Ck45 steel. Care has been taken to keep the parallelism tolerance below $0.01 \mathrm{~mm}$ in order to prevent deflection during the operation. For this reason, the bottom and surfaces of the plates were grinded in Ra 0.8 quality. Punch with countersunk head made of 1.2210 material, which is a ready-to-assemble mold element, is used for the pins that ensure that the springs are centered and not removed during operation. It was assembled with the manufactured plates and other ready-to-assemble equipment, then, it was assembled into a base designed with aluminum profiles. The machine control

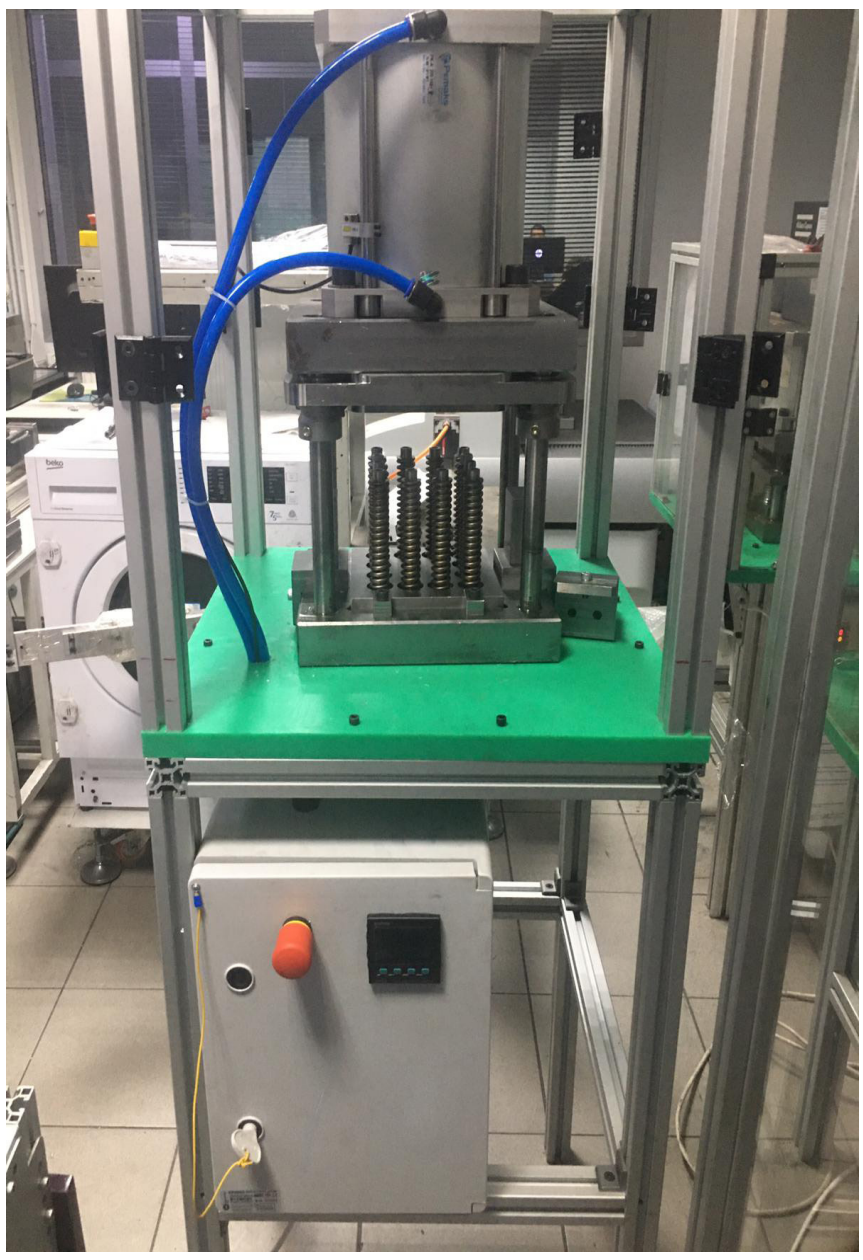

Figure 7. Compression spring fatigue machine. unit and pneumatic valve are installed in an enclosure box. Emergency stop button and counter are mounted on the enclosure box with an easily accessible manner.

The highest speed is 60 compression cycles per minute, as the maximum operating speed is controlled by the multi-function time relay. This speed must run for 27.7 hours to complete 100000 fatigue cycles. The most important reason for the low working speed is also related to the closing time of the pneumatic cylinder and limit of air pressure line.

\section{CONCLUSION}

In this study, a fatigue device is designed to simulate fatigue behavior of compression springs. In the design, it has been designed in a way to make the fatigue of 12 springs together in order to be statistically correct. The working system has been designed successfully and it has been observed that there is no problem in its operation. Since it imitates the same life values encountered in real life, it is assumed to draw the closest possible result. It is practical and convenient to use. However, further development of the system in terms of speed and instantaneous force measurement, inability to monitor S-N and strength values of the springs simultaneously constitute its main deficiencies.

\section{REFERENCES}

[1] Kong, Y.S., Abdullah, S., Schramm, D., Omar, M.Z., Haris, S.M., Bruckmann, T. (2017). Mission profiling of road data measurement for coil spring fatigue life. Measurement: Journal of the International Measurement Confederation. 107: 99-110. doi: 10.1016/j.measurement.2017.05.011.

[2] Zhang, P., Wang, D., Guo, Y., Cheng, P., Shao, C., Lang, N., et al., (2020). Fatigue failure analysis and finite element assessment of the twins torsion spring. Engineering Failure Analysis. 122(July 2020): 105187. doi: 10.1016/j.engfailanal.2020.105187.

[3] Mohammad Hashemi, Y., Kadkhodaei, M., Mohammadzadeh, M.R., (2019). Fatigue analysis of shape memory alloy helical springs. International Journal of Mechanical Sciences. 161-162(July). doi: 10.1016/j.jijmecsci.2019.105059.

[4] Drummen, I., Storhaug, G., Moan, T. (2008). Experimental and numerical investigation of fatigue damage due to wave-induced vibrations in a containership in head seas. Journal of Marine Science and Technology. 13(4): 428-45. doi: 10.1007/s00773-008-0006-5.

[5] Pyttel, B., Brunner, I., Kaiser, B., Berger, C., Mahendran, M. (2014). Fatigue behaviour of helical compression springs at a very high number of cycles - Investigation of various influences. International Journal of Fatigue. 60: 101-9. doi: 10.1016/j.jffatigue.2013.01.003.

[6] Močilnik, V., Gubeljak, N., Predan, J., Flašker, J. (2010). The influence of constant axial compression pre-stress on the fatigue failure of torsion loaded tube springs. Engineering Fracture Mechanics. 77(16): 3132-42. doi: 10.1016/j.engfracmech.2010.07.014.

[7] Li, W., Sakai, T., Wakita, M., Mimura, S., (2014). Influence of microstructure and surface defect on very high cycle fatigue properties of clean spring steel. International Journal of Fatigue. 60: 48-56. doi: 10.1016/j.jfatigue.2013.06.017.

[8] Bi, S., Li, Y., Zhao, H., (2019). Fatigue analysis and experiment of leaf-spring pivots for high precision flexural static balancing instruments. Precision Engineering. 55(October 2018): 408-16. doi: 
10.1016/j.precisioneng.2018.10.009.

[9] Berger, C., Kaiser, B., (2006). Results of very high cycle fatigue tests on helical compression springs. International Journal of Fatigue. 28(11): 1658-63. doi: 10.1016/j.ijfatigue.2006.02.046.

[10] Akiniwa, Y., Stanzl-Tschegg, S., Mayer, H., Wakita, M., Tanaka, K., (2008). Fatigue strength of spring steel under axial and torsional loading in the very high cycle regime. International Journal of Fatigue. 30(12): 2057-63. doi: 10.1016/j.ijfatigue.2008.07.004. 